Original Research Article

\title{
Study of lipid lowering effects of oral antidiabetic drugs in type 2 diabetes mellitus patients
}

\author{
Shashikala E. ${ }^{1 *}$, Somnath Motgi ${ }^{1}$, Raghawa Rao B. N. V. ${ }^{2}$, Mohd Abdul Sattar ${ }^{3}$
}

${ }^{1}$ Department of Pharmacology, ${ }^{2}$ Department of Cardiology, ${ }^{3}$ Department of Diabetology, Mallareddy Institute of Medical Sciences, Hyderabad, Telangana, India

Received: 30 October 2017 Accepted: 24 November 2017

\section{*Correspondence to: \\ Dr. Shashikala E., \\ Email: drvijayragava \\ @gmail.com}

Copyright: (c) the author(s), publisher and licensee Medip Academy. This is an openaccess article distributed under the terms of the Creative Commons Attribution NonCommercial License, which permits unrestricted noncommercial use, distribution, and reproduction in any medium, provided the original work is properly cited.

\begin{abstract}
Background: Type 2 diabetes mellitus (T2DM) is one of the most common noncommunicable diseases associated with 'atherogenic dyslipidemia' The treatment of T2DM often is initiated with oral antidiabetic drugs, most of which not only decrease blood sugar levels effectively but also decrease the lipid levels. Hence the current study is aimed to determine the effectiveness of oral hypoglycemic agents in dealing with associated dyslipidemia.

Methods: 150 T2DM patients were divided equally into five groups depending upon the oral antidiabetic drugs they received in solo or in combination for 24 weeks, with equal number of males and females in each group. After the written consent, a detail clinical history, clinical examination, Biochemical investigations including, glycosylated haemoglobin and lipid profile, chest X-ray and ECG were done.

Results: After 24 weeks of study, the mean total cholesterol and mean triglycerides decreased significantly ( $p<0.05$ to $p<0.01$ ) with monotherapy of metformin and teneligliptin as well as with combination of either metformin and glimepiride or metformin and teneligliptin. The decrease of LDL-C and VLDL$\mathrm{C}$ was not statistically significant with any of the OAD drugs in solo or in combination. Similarly, HDL-C increased significantly $(p<0.05)$ in Group I, III, IV and V; but was most effective with combination therapy. The atherogenic index of plasma also decreased $(\mathrm{p}<0.05)$ with metformin or its combination with either teneligliptin or glimepiride.

Conclusions: Oral antidiabetic drugs are not only affordable and effective hypoglycemic agents but can also decrease serum lipids and thereby aids in the prevention and management of atherosclerosis and its complications in T2DM.
\end{abstract}

Keywords: Affordable, Lipid profile, Lipid lowering effects, Oral antidiabetic drugs, T2DM

\section{INTRODUCTION}

Diabetes mellitus (DM)is a global public health problem. The World Health Organization (WHO) predicts and estimates that the number of people with DM in the world will be 300 million by $2025 .^{1,2} \mathrm{DM}$ is a progressive disorder and is one of modifiable risk factors for the development of cardiovascular diseases, nephropathy and retinopathy. The incidence of cardiovascular diseases (CVDs) and diabetes mellitus is rising, and India will be the diabetic capital of the world by 2020 (World Health Report, 2002). ${ }^{3,4}$

DM is known to be associated with alterations in lipid metabolism and abnormalities in serum lipid profile, characterized by low HDL-C, high triglycerides and total cholesterol and normal or raised LDL-C, which results in "Atherogenic Dyslipidemia" and worsens the prognosis of diabetic patients by synergistically accelerating the atherosclerosis and development of CVD. It has been hypothesized that most of the oral anti-diabetic drugs have 
significant lipid lowering effect besides achieving effective glycaemic control and thus can modify dyslipidemia and help in decreasing the risk of atherosclerosis, coronary heart disease, stroke, nephropathy and retinopathy.

Hence the current study is focused to determine which common oral anti-diabetic drugs in solo or in combination are most effective in lowering serum lipids and thereby enhance our approach to drug selection for the best management of T2DM.

\section{METHODS}

This is a Prospective comparative study of T2DM patients conducted in the Departments of Pharmacology and Medicine, Mallareddy Institute of Medical Sciences and Hospital, Suraram, Hyderabad, TS, after the Institutional Ethical Committee approval.

DM was diagnosed as per 2016 American Diabetic Association (ADA)guide lines. ${ }^{5}$

Patients who were smokers, alcoholic, with coronary artery disease (CAD), chronic kidney disease and retinopathy and those on lipid lowering drugs were excluded from the study

After written consent from each patient, a detailed Clinical history, Clinical examination, Biochemical investigations Fasting blood sugar (FBS), Post prandial blood sugar (PPS), Glycosylated haemoglobin (HBA1c, done by High performance liquid chromatography), serum creatinine, serum electrolytes and Lipid profile were done.

Lipid profile included: total cholesterol (TC), triglycerides (TG) and high-density lipoprotein cholesterol (HDL-C) (done enzymatically by using a kit), low density lipoprotein cholesterol (LDL-C) and very low-density lipoprotein cholesterol (VLDL-C) (calculated by using the Fried Wald formula). ${ }^{6-8}$

Chest X-ray and electrocardiogram (ECG) were also done. Patients were categorized into five Groups:

- Group I: T2DM patients received Metformin 500$1000 \mathrm{mg} /$ day only.

- Group II: T2DM patients received Glimepiride(1/2mg/day) only

- Group III: T2DM patients received Teneligliptin $20 \mathrm{mg} /$ day only

- Group IV: T2DM patients received Metformin (500$1000 \mathrm{mg} /$ day) and Glimepiride(1/2mg/day)

- Group V: T2DM patients received Metformin (500$1000 \mathrm{mg} /$ day) and Teneligliptin $(20 \mathrm{mg} /$ day)

Repeat HBA1c and Lipid profile were done after 12 and 24 weeks of treatment with oral anti diabetic $\operatorname{drugs}(\mathrm{OADD})$.

\section{Statistical analysis}

The data obtained from the study are presented as mean with standard deviation and percentage and results are assessed by using Student's $t$ test; $P<0.05$ values are considered as statistical significance

\section{RESULTS}

\section{Clinical characteristics}

This study consisted of 150 T2DM patients with 100 males and 50 females with age ranging from 33 to 65 years with a mean of $49.48 \pm 7.8$ years. Each Group consisted of 30 patients with 20 males $(66.67 \%)$ and 10 females (33.33\%).

In Group I the age of the patients ranged between 3563years with a mean of $48.75 \pm 7.7$ years; in Group II it was $38-65 y e a r s$ with a mean of $47.68 \pm 8.5$ years; in Group III it was 35-65 years with a mean of $51.83 \pm 8.3$ years; in Group IV it is 33-64years with a mean of $49.58 \pm 8.2$ years, and in Group V the age ranged between 37-61 years with a mean of $49.58 \pm 6.1$ years (Figure 1).

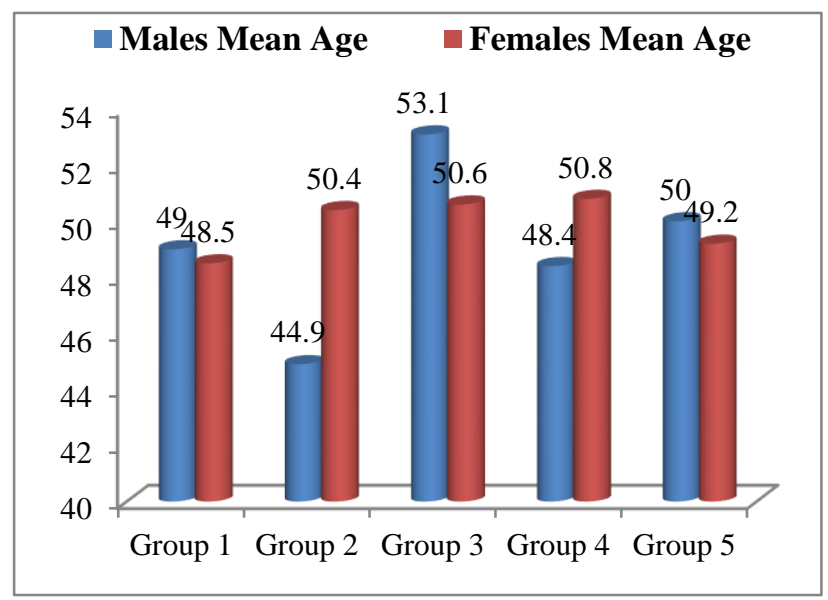

Figure 1: Mean age of the patients in years.

The duration of DM in this study ranged from 2 years to 9 years with a mean of $4.05 \pm 2.3$ years. In Group I duration ranged from $2-9$ years with a mean of $4.03 \pm 1.8$ years; in Group II it was 2-9 years with a mean of $4.2 \pm 1.8$ years; in Group III it was 2-8years with a mean of $4.1 \pm 1.5$ years; in Group IV it was 2-8years with a mean of $4.3 \pm 1.8$ years and in Group $V$ the duration of DM was 2-6 years with a mean of $3.5 \pm 1.4$ years (Figure 2).

\section{Routine investigations}

The routine biochemical investigations: serum creatinine, and serum electrolytes were within Normal limits. However, 10 patients $(6.67 \%)$ of the study had cardiomegaly and left ventricular hypertrophy (LVH) on X-ray chest (PA view) and standard ECG who had concomitant hypertension. 


\section{Blood sugar}

The Initial FBS, PPS and HBA1c were high and in the diabetic range in all patients as per ADA criteria. ${ }^{5}$

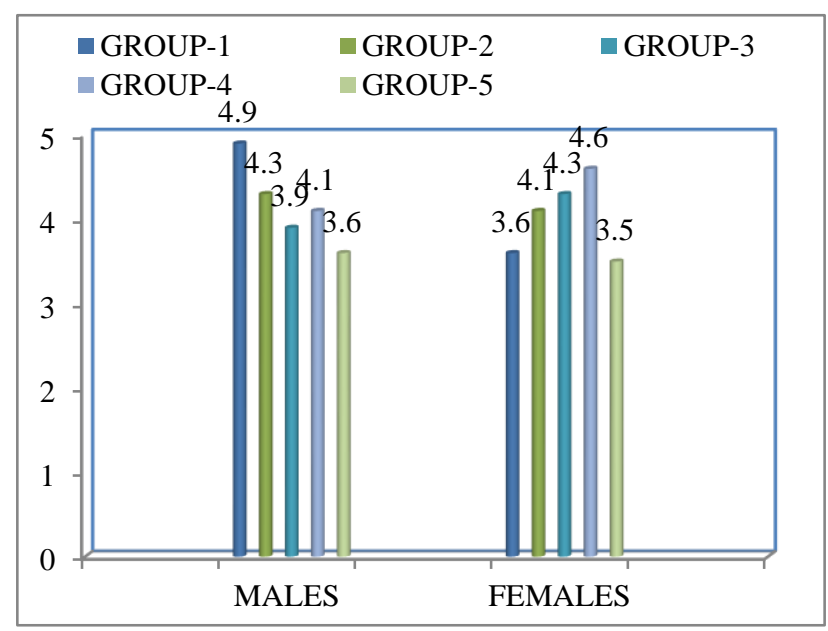

Figure 2: Mean duration of T2DM in the study.

The mean HBA1c significantly decreased in all patients after 24 weeks of treatment. The mean HBA1c decreased from $8.4 \%$ to $7.5 \%(0.88,10.50 \%, p<0.001)$ in Group I; from $8.5 \%$ to $7.7 \%(0.76,9.0 \%, p<0.01)$ in Group II; from $8.5 \%$ to $7.6 \%(0.88,10.29 \%, p<0.01)$ in Group III; from $8.6 \%$ to $7.3 \%(1.25,14.61 \%, p<0.001)$ in Group IV; and it decreased from $8.8 \%$ to $7.3 \%(1.49,16.95 \%, p<0.001)$ in Group V diabetic patients (Table 1).

However only $4(13.33 \%)$ patients in Group I, 2 ((6.67\%) patients in Group II, 5 (16.66\%) patients in Group III, 8 (26.67\%) patients in Group IV and 7 (23.33\%) patients in Group V achieved $<7 \%$ of HBA1c.

\section{Lipid profile}

Dyslipidemia was present in all patients in all Groups. After 24 weeks of study, the mean total cholesterol(TC) decreased significantly in GI from $223.3 \mathrm{mg} / \mathrm{dl}$ to $199.7 \mathrm{mg} / \mathrm{dl}(10.17 \%, p<0.05)$; in Group III from $211.8 \mathrm{mg} / \mathrm{dl}$ to $194.3 \mathrm{mg} / \mathrm{dl}(8.26 \%, p<0.05)$; in Group IV from $229.3 \mathrm{mg} / \mathrm{dl}$ to $194.7 \mathrm{mg} / \mathrm{dl}(15.07 \%, p<0.01)$ and in Group V from $245.9 \mathrm{mg} / \mathrm{dl}$ to $206.2 \mathrm{mg} / \mathrm{dl}(16.14 \%, p$ $<0.01)$; while in Group II TC decreased only by $5.02 \%(p$ $>0.05$ ) from $232.9 \mathrm{mg} / \mathrm{dl}$ to $221.2 \mathrm{mg} / \mathrm{dl}$.

Table 1: Glycaemic status in type 2 diabetic patients on oral antidiabetic drugs.

\begin{tabular}{|lllllll|}
\hline Blood sugar & & Group I & Group II & Group III & Group IV & Group V \\
\hline \multirow{3}{*}{1. HBA1c } & Initial mean & $8.4 \pm 0.6$ & $8.5 \pm 1.0$ & $8.5 \pm 1.1$ & $8.6 \pm 1.1$ & $8.8 \pm 1.2$ \\
\cline { 2 - 7 } & After 24 wks & $7.5 \pm 0.5$ & $7.7 \pm 1.1$ & $7.6 \pm 1.0$ & $7.3 \pm 1.0$ & $7.3 \pm 0.9$ \\
\cline { 2 - 7 } & \multirow{2}{*}{$\%$ of $\downarrow$} & $\begin{array}{l}0.88(10.50 \%) \\
(\mathrm{p}<0.001)\end{array}$ & $\begin{array}{l}0.76(9.0 \%) \\
(\mathrm{p}<0.01)\end{array}$ & $\begin{array}{l}0.88(10.29 \%) \\
(\mathrm{p}<0.01)\end{array}$ & $\begin{array}{l}1.25(14.61 \%) \\
(\mathrm{p}<0.001)\end{array}$ & $\begin{array}{l}1.49(16.95 \%) \\
(\mathrm{p}<0.001)\end{array}$ \\
\hline
\end{tabular}

Table 2: Lipid lowering effects of oral antidiabetic drugs in type 2 diabetic patients.

\begin{tabular}{|lllllll|}
\hline \multicolumn{2}{|l}{ Lipid parameters } & Group I & Group II & Group III & Group IV & Group V \\
\hline \multirow{2}{*}{$\begin{array}{l}\text { Total } \\
\text { cholesterol } \\
(\mathrm{mg} / \mathrm{dl})\end{array}$} & Initial mean & $222.3 \pm 36.2$ & $232.9 \pm 30.2$ & $211.8 \pm 33.34$ & $229.3 \pm 37.3$ & $245.9 \pm 40.2$ \\
\cline { 2 - 7 } & After $24 \mathrm{wks}$ & $199.7 \pm 33.4$ & $221.2 \pm 27.3$ & $194.3 \pm 30.2$ & $194.7 \pm 30.3$ & $206.2 \pm 38.3$ \\
\hline \multirow{2}{*}{$\begin{array}{l}\text { Triglycerides } \\
(\mathrm{mg} / \mathrm{dl})\end{array}$} & $\begin{array}{l}10.17 \%(\mathrm{p}<0.0 \\
5)\end{array}$ & $5.02 \%$ & $8.26 \%(\mathrm{p}<0.05)$ & $15.07 \%(\mathrm{p}<0.01)$ & $16.14 \%(\mathrm{p}<0.01)$ \\
\cline { 2 - 7 } & Initial mean & $262.2 \pm 35.3$ & $241.2 \pm 34.3$ & $235.9 \pm 30.3$ & $251.5 \pm 36.3$ & $246.8 \pm 36.2$ \\
\hline
\end{tabular}

Table 3: Effects of oral antidiabetic drugs on lipids in type 2 diabetic patients.

\begin{tabular}{|c|c|c|c|c|c|c|}
\hline \multicolumn{2}{|c|}{ Lipid parameters } & Group I & Group II & Group III & Group IV & Group V \\
\hline \multirow{3}{*}{$\begin{array}{l}\text { LDL-C } \\
(\mathrm{mg} / \mathrm{dl})\end{array}$} & Initial mean & $134.9 \pm 40.2$ & $153.0 \pm 46.3$ & $129.5 \pm 30.4$ & $145.2 \pm 40.3$ & $151.1 \pm 46.2$ \\
\hline & After $24 w k s$ & $128.0 \pm 45$ & $148.4 \pm 36.4$ & $123.0 \pm 28.2$ & $130.7 \pm 38.2$ & $135.6 \pm 36.3$ \\
\hline & $\%$ of $\downarrow$ & $6.9 \%$ & $3.0 \%$ & $5.02 \%$ & $10.0 \%$ & $10.26 \%$ \\
\hline \multirow{3}{*}{$\begin{array}{l}\text { VLDL-C } \\
(\mathrm{mg} / \mathrm{dl})\end{array}$} & Initial mean & $52.9 \pm 11.2$ & $48.4 \pm 6.3$ & $48.2 \pm 5.3$ & $49.9 \pm 7.2$ & $51.8 \pm 7.3$ \\
\hline & After $24 w k s$ & $50.2 \pm 10.3$ & $46.9 \pm 6.2$ & $45.7 \pm 5,2$ & $44.9 \pm 6.1$ & $46.6 \pm 6.1$ \\
\hline & $\%$ of $\downarrow$ & $5.10 \%$ & $3.10 \%$ & $5.19 \%$ & $10.02 \%(\mathrm{p}<0.01)$ & $10.04 \%(\mathrm{p}<0.01)$ \\
\hline \multirow{3}{*}{$\begin{array}{l}\text { HDL-C } \\
\text { (mg/dl) }\end{array}$} & Initial mean & $35.5 \pm 3.3$ & $36.1 \pm 6.1$ & $35.6 \pm 4.1$ & $36.5 \pm 4.3$ & $36.1 \pm 4.1$ \\
\hline & After $24 w k s$ & $38.3 \pm 3.2$ & $38.2 \pm 6.1$ & $38.4 \pm 5.1$ & $40.9 \pm 4.2$ & $41.6 \pm 4.2$ \\
\hline & $\%$ of $\uparrow$ & $6.27 \%(\mathrm{p}<0.05)$ & $5.82 \%$ & $7.87 \%(\mathrm{p}<0.05)$ & $12.05 \%(\mathrm{p}<0.001)$ & $15.23 \%(\mathrm{p}<0.001)$ \\
\hline
\end{tabular}


However, TC reduced to $<200 \mathrm{mg} / \mathrm{dl}$ only in $50 \%$. $19(12.67 \%)$ patients in Group I, $9(6 \%)$ patients in Group II, 17(11.33\%) patients in Group III, 16(10.67\%) patients in Group IV and 14(9.33\%) patients in Group V could only achieve the TC level target.

The mean triglycerides (TG) decreased from significant to highly significant in patients of Group I,III, IV and V ( $p$ $<0.05$ to $p<0.001$ ). The mean TG decreased significantly in Group I from $262.2 \mathrm{mg} / \mathrm{dl}$ to $243.8 \mathrm{mg} / \mathrm{dl}(7.01 \%, p$ $<0.05)$; in Group III from $235.9 \mathrm{mg} / \mathrm{dl}$ to $219.3 \mathrm{mg} / \mathrm{dl}$ (7.03\%, $p<0.05)$; in Group IV from $251.5 \mathrm{mg} / \mathrm{dl}$ to $221.1 \mathrm{mg} / \mathrm{dl}(12.01 \%, p<0.01)$ and in Group V from $246.8 \mathrm{mg} / \mathrm{dl}$ to $209.6 \mathrm{mg} / \mathrm{dl}(15.02 \%, p<0.01)$; while in Group II it decreased by only $5.03 \%, p>0.05$ ) from $241.2 \mathrm{mg} / \mathrm{dl}$ to $229.1 \mathrm{mg} / \mathrm{dl}$ (Table 2 ).

However, $<200 \mathrm{mg} / \mathrm{dl}$ of TG was achieved only in $34.67 \%$. $9(6 \%)$ patients in Group I, $10(6 \%)$ patients in Group II; $12(8 \%)$ patients in Group III; $9(6 \%)$ patients in Group IV and 12(8\%) patients in Group V reached the target of $<200 \mathrm{mg} / \mathrm{dl}$ of TG and only 6 patients (4\%), 2 each in Group III, Group IV and Group V attained $\leq 150 \mathrm{mg} / \mathrm{dl}$ of TG level.
The mean LDL-C decreased in all patients with single or combinations of OADD from $3 \%$ to $10.26 \%$, but was not statistically significant. In patients in Group I, LDL-C decreased by $6.9 \%$; in Group II by $3.0 \%$; in Group III by $5.02 \%$; in Group IV by $10.0 \%$ and in Group V it decreased by $10.26 \%$.

Similarly mean VLDL-C even though decreased in all patients from $3.10 \%$ to $10,04 \%$, it was also not statistically significant. In patients in Group I, VLDL-C decreased by $5.10 \%$; in Group II, by $3.10 \%$; in Group III, by $5.19 \%$; in Group IV by $10.02 \%$ and in Group V it decreased by $10.04 \%$

The mean HDL-C also increased significantly and reached $\geq 40 \mathrm{mg} / \mathrm{dl}$ in patients of Group IV and V. The HDL-C increased in Group I from $35.5 \mathrm{mg} / \mathrm{dl}$ to $38.3 \mathrm{mg} / \mathrm{dl}(7.89 \%$, $p<0.05)$; in Group III from $35.6 \mathrm{mg} / \mathrm{dl}$ to $38.4 \mathrm{mg} / \mathrm{dl}(7.87 \%, p<0.05)$; in G IV from $36.5 \mathrm{mg} / \mathrm{dl}$ to $40.9 \mathrm{mg} / \mathrm{dl}(12.05 \%, p<0.001)$ and in Group $\mathrm{V}$ from $36.1 \mathrm{mg} / \mathrm{dl}$ to $41.6 \mathrm{mg} / \mathrm{dl}(15.23 \%, p<0.001)$ while it only it increased by only $5.82 \%,(p>0.05)$ in Group II from $36.1 \mathrm{mg} / \mathrm{dl}$ to $38.2 \mathrm{mg} / \mathrm{dl}$ (Table 3 ).

Table 4: Effects of oral antidiabetic drugs on atherogenic index of plasma in type 2 diabetic patients.

\begin{tabular}{|lllllll|}
\hline Lipid parameters & Group I & Group II & Group III & Group IV & Group V \\
\cline { 2 - 7 } TC/HDL- & Initial mean & $6.6 \pm 1.3$ & $5.9 \pm 1.2$ & $5.9 \pm 1.1$ & $6.5 \pm 1.3$ & $6.2 \pm 1.1$ \\
\cline { 2 - 7 } C Ratio & After 24 wks & $5.6 \pm 1.2$ & $5.7 \pm 1.2$ & $5.1 \pm 1.1$ & $4.8 \pm 0.8$ & $5.0 \pm 1.2$ \\
\cline { 2 - 7 } & $\%$ of $\downarrow$ & $15.15 \%(\mathrm{p}<0.05)$ & $9.5 \%$ & $13.55 \%(\mathrm{p}<0.05)$ & $26.15 \%(\mathrm{p}<0.001)$ & $19.35 \%(\mathrm{p}<0.001)$ \\
\hline
\end{tabular}

The atherogenic index of plasma (the ratio of TC/HDL-C) decreased significantly by $15.15 \%$ in Group I ( $p>0.05)$; by $13.55 \%$ in Group III $(p>0.05)$; by $26.15 \%$ in Group IV ( $p$ $>0.001)$ and by $19.35 \%$ in Group V $(p>0.001)$. However, in the present study, the ratio of TC/HDL-C of $\leq 4.5$ was achieved only in $19.33 \%$. 2 patients in Group I, and 9 patients each in Group III, Group IV and Group V (Table $4)$.

\section{DISCUSSION}

\section{Glycemic effects of oral antidiabetic drugs (OADD)}

In the present study HBA1c decreased significantly in all patients, but non-diabetic levels of $<7 \%$ of HBA1c achieved only in $17.33 \%$ of patients after 24 weeks of treatment with metformin, glimepiride, teneligliptin or their combinations. A combination of metformin and glimepiride was more effective in which $26.67 \%$ of T2DM patients achieved the optimum levels of Glycosylated HB levels.

Similar observation of effectiveness of combination of metformin and glimepiride was made by Haupt $\mathrm{E}$ et $\mathrm{al}^{9}$ and Riddle M. ${ }^{10}$ However Kim MK reported to achieve $<7 \%$ of HBA1c in $64.71 \%$ of T2DM with combination of metformin and teneligliptin while in present study it was only in $23.33 \%$ with this combination of therapy. ${ }^{11}$

\section{Lipid lowering effects of $O A D D$}

In this study Metformin, a biguanide; Glimepiride, a second-generation sulfonylurea; Teneligliptin, a thirdgeneration dipeptidyl peptidase (DPP)-4 inhibitor and their combinations were used as oral antidiabetic drugs.

DM is always associated with alterations in lipid metabolism and abnormalities in serum lipid profile i.e. "atherogenic dyslipidemia." dyslipidemia is usual in T2 Diabetic patients with poorly controlled glycemia. ${ }^{12}$ So in the present study also all 150 T2DM patients were having dyslipidemia

\section{Effect on total cholesterol}

After 24 weeks of study, the mean TC decreased significantly in patients with combined therapy of metformin and teneligliptin (16.14\%) and metformin and glimepiride $(15.07 \% \%)$; while monotherapy with metformin, mean TC decreased by $10.17 \%$, with 
teneligliptin by $8.26 \%$ and with glimepiride it decreased by $5.02 \%$ only. The present study also revealed that the treatment with metformin alone and its combination with glimepiride or teneligliptin was found to be effective in reducing TC to $<200 \mathrm{mg} / \mathrm{dl}$.

\section{Effect on triglycerides}

Similarly, monotherapy with metformin than glimepiride was better in reducing mean TG levels in this study $(7.01 \%$ vs $5.03 \%$ ) while combination of metformin with either glimepiride or teneligliptin was superior in reduction of mean TG levels significantly $(12.01 \%$ and $15.07 \%$ respectively). However, $\leq 150 \mathrm{mg} / \mathrm{dl}$ of $\mathrm{TG}$ was achieved only in $4 \%$ in this study with either teneligliptin or combination therapy.

The beneficial effects of metformin on lipids could be due to inhibition of fatty acids release from adipose tissues, its direct effect on VLDL-C metabolism and/or secondary to improved insulin sensitivity. ${ }^{13}$

Metformin was also shown to decrease TC in T2DM patients, in the Turkish patients, it was reported reduction of TC and TG with an increase of HDL-C with metformin therapy similar to present study. ${ }^{14-18}$ But authors reported no change in lipid profile in their studies on T2DM treated with metformin. ${ }^{19,20}$

The beneficial effects of teneligliptin on lipids in the studies, especially reduction of postprandial TG. ${ }^{21,22}$

\section{Effect on low density lipoprotein cholesterol}

In present study reduction of mean LDL-C was not statistically significant. The combination therapy of metformin and glimepiride or metformin and teneligliptin was better in reducing of LDL-C (decrease of $10.0 \%$ and $10.26 \%$ respectively). However, a meta-analysis by Hongmei $\mathrm{Zhu}$ et $\mathrm{al}^{23}$ found that in T2DM patients metformin was more effective than glimepiride in reducing TC, TG as well as LDL-C. Similarly, a metaanalysis by Wulffle $\mathrm{MG}$ et al showed efficacy of metformin in reducing TC, TG and LDL-C in their study with at least 6 weeks of treatment in T2 DM. ${ }^{24}$

\section{Effect on very low density lipoprotein cholesterol}

Similarly, reduction of mean VLDL-C was not statistically significant in the present study and similarly combination therapy of metformin with glimepiride or with teneligliptin was better in reduction of VLDL-C (decrease of $10.02 \%$ and $10.04 \%$ respectively)

\section{Effect on high density lipoprotein cholesterol and TC/HDL-C ratio}

In this study monotherapy with metformin or glimepiride or teneligliptin for 24 weeks could not increase HDL-C to desired and optimal levels $(\geq 40 \mathrm{mg} / \mathrm{dl})$, but it increased significantly in patients treated with combination of metformin and glimepiride ( $\uparrow$ of $12.05 \%, \mathrm{p}<0.001)$ or metformin and teneligliptin ( $\uparrow$ of $15.23 \%$, p <0.001)

A significant decrease in TC, TG and LDL-C and increase in levels of HDL-C was also reported after 3 months of treatment with metformin in T2DM patients. ${ }^{25}$

Pravin Kumar V Ingle and Gokul S Talele reported a decrease of $16 \%, 12 \%$ and $10 \%$ of TC, TG and LDL-C respectively and a $15 \%$ increase of HDL-C; and achieving the lipid control goals with metformin - glimepiride combination therapy of 26 weeks in T2DM in their study. ${ }^{26}$

The mean atherogenic index of plasma significantly decreased in patients treated with metformin alone or with combination therapy, but ratio of TC/HDL-C $\leq 4.5$ was achieved only in $19.33 \%$ in this study.

The economic impact of diabetes specially T2DM is substantial not only on the individuals but also on the society and country especially in a developing country like ours. This impact is more vulnerable and visible in middle and lower income Groups of the society. ${ }^{27}$

Hence in this scenario, the present study supports the initiation of treatment of T2DM with metformin, which is affordable and effective in decreasing the glycemic as well as lipid levels; together with lifestyle modifications (diet, exercise, avoidance of alcohol, quitting smoking). A combination therapy of metformin either with glimepiride or affordable DPP-4 inhibitor (Teneligliptin) or insulin should be initiated if ideal levels of HBA1c is not achieved after three months of treatment. ${ }^{28}$ Similarly, triple drug therapy should be initiated if treatment is not satisfactory because optimum glycemic level is a must for the reduction of elevated lipid levels and thereby preventing atherosclerosis and its complications. However, some patients may require additional specific lipid lowering agents such as statins to achieve desired and optimal levels of lipids

\section{CONCLUSION}

Present study showed dyslipidemia in all T2DM patients:

- $\quad$ All OAD drugs were effective in reducing HBA1c but could not achieve non-diabetic levels after 24 weeks of therapy in all.

- The monotherapy with metformin than glimepiride was better in reducing mean TC and mean TG levels while combination of metformin with either glimepiride or teneligliptin was superior in achieving in reduction of TC and TG levels significantly

- In present study reduction of LDL-C and VLDL-C was not statistically significant and only combination therapy of metformin with glimepiride or with teneligliptin was better 
- HDL-C increased significantly in patients treated with combination of metformin and glimepiride or metformin and teneligliptin

- The atherogenic index of plasma could be decreased significantly with metformin or its combination with teneligliptin or glimepiride

- The economic impact of T2DM is substantial specially in middle and low-income strata of the society. Hence the management of T2DM can be initiated with metformin, which is affordable and effective in decreasing the glycemic and lipid levels, together with lifestyle modifications

- Most of the T2DM may require a combination of metformin and glimepiride or metformin and teneligliptin for decreasing glycemic and lipid levels at a later stage

- Some patients may require additional specific lipid lowering agents such as statins to achieve desired and optimal levels of lipids

\section{ACKNOWLEDGEMENTS}

Authors would like to thank Prof. T. Srinivas formerly Prof and HOD of Medicine, Dean, Medical Superintendent and Management of Mallareddy Institute of Medical Sciences and Hospital, Suraram, Hyderabad for allowing me to conduct this study in the Medical Wards and OPD, and to all my patients who fully cooperated in conducting this study.

Funding: No funding sources

Conflict of interest: None declared

Ethical approval: The study was approved by the Institutional Ethics Committee

\section{REFERENCES}

1. American Diabetes Association. Role of cardiovascular risk factors in prevention and treatment of macrovascular disease in diabetes. Diabetes Care. 1993;16:72-8.

2. Smyth S, Heron A. Diabetes and obesity: the twin epidemics. Nature medicine. 2006;12(1):75-80.

3. Ahlawat SK, Singh MM, Kumar R, Kumari S, Sharma BK. Time trends in the prevalence of hypertension and associated risk factors in Chandigarh. J Indian Med Assoc. 2002;100(9):547-52.

4. Kumar A, Nagtilak S, Sivakanesan R, Gunasekera S. Cardiovascular Risk Factors in Elderly Normolipidemic Acute Myocardial Infarct Patients- A Case Controlled Study from India. Southeast Asian J Trop Med Public Health. 2009;40(3):581-92.

5. American Diabetes Association. Standard of Medical care in Daibetes-2016. Diabetes Care. 2016;39:S1S106.

6. Richmond W. Preparation and Properties of a Cholesterol Oxidase from Nocardia species and its application to the enzymatic assay of Total Cholesterol in serum. Clin Chem. 1973;19:1350-6.
7. Foosati P, Prencipe L. Serum triglycerides determined calorimetrically with an enzyme that produces hydrogen peroxide. Clin Chem. 1982;28:2077-80.

8. Friedewald WT, Levy RI, Fredrickson DS. Estimation of the concentration of low-density lipoprotein cholesterol in plasma, without use of the preparative ultracentrifuge. Clin Chem. 1972;18:499-502.

9. Haupt E, Knick B, Koshinsky T, Liebermeister H, Schneider $\mathbf{J}$ and Hirche $\mathrm{H}$. oral antidiabetic combination therapy with Sulphonylurea and metformin. Diabet Metab. 1991;17:224-31.

10. Riddle M. Combining sulphonylureas and other oral agents. Am J Med. 2000;1086a:155-225.

11. Kim MK, Rhee EJ, Han KA, Woo AC, Lee MK, Ku BJ, et al. Efficacy and safety of teneligliptin, a dipeptidyl peptidase-4 inhibitor, combined with metformin in Korean patients with type 2 diabetes mellitus: a 16-week, randomized, double-blind, placebo-controlled phase III trial. Diabetes, Obesity and Metabolism. 2015;17(3):309-12.

12. Gibbons GF. Hyperlipidemia of diabetes mellitus. Clin Sci. 1988;71:477-86

13. Abbasi F, Kamath V, Rizvi AA, Carantoni M, Chen YD, Reaven GM. Results of a placebo-controlled study of the metabolic effects of the addition of metformin to sulfonylurea-treated patients: evidence for a central role of adipose tissue. Diabet care. 1997;20(12):1863-9.

14. Cagatay P, Susleyici-Duman B, Alasya H, Ipbuker A. Effects of oral antidiabetic drugs over lipid parameters in Turkish type 2 diabetes patients. Acta Med Acad. 2009;38(2):77-85.

15. Ginsberg H, Plutzky J, Sobel BE. A review of metabolic and cardiovascular effects of oral antidiabetic agents: beyond glucose level lowering. J Cardiovasc Risk. 1999;6:337-46.

16. Grant PJ. The effects of high-and medium-dose metformin therapy on cardiovascular risk factors in patients with type II diabetes. Diabetes care. 1996 Jan 1;19(1):64-6.

17. Yki-Järvinen H, Ryysy L, Nikkilä K, Tulokas T, Vanamo R, Heikkilä M. Comparison of Bedtime Insulin Regimens in Patients with Type 2 Diabetes MellitusA Randomized, Controlled Trial. An Int Med. 1999;130(5):389-96.

18. Robinson AC, Burke J, Robinson S, Johnston DG, Elkeles RS. The effects of metformin on glycemic control and serum lipids in insulin-treated NIDDM patients with suboptimal metabolic control. Diabet Care. 1998;21(5):701-5.

19. Groop L, Widen E, Franssila-Kallunki A, Ekstrand A, Saloranta C, Schalin C, et al. Different effects of insulin and oral antidiabetic agents on glucose and energy metabolism in type 2 (non-insulin-dependent) diabetes mellitus. Diabetologia. 1989;32(8):599-605.

20. Rains SG, Wilson GA, Richmond W, Elkeles RS. The effect of glibenclamide and metformin on serum lipoproteins in type 2 diabetes. Diabet Med. 1988;5(7):653-8. 
21. Ansar S, Koska J, Reaven PD. Postprandial hyperlipidemia, endothelial dysfunction and cardiovascular risk: focus on incretins. Cardiovasc diabetol. 2011;10(1):61.

22. Fukuda-Tsuru S, Anabuki J, Abe Y, Yoshida K, Ishii S. A novel, potent, and long-lasting dipeptidyl peptidase-4 inhibitor, teneligliptin, improves postprandial hyperglycemia and dyslipidemia after single and repeated administrations. Eur J Pharmacol. 2012;696(1):194-202.

23. Zhu H, Zhu S, Zhang X, Guo Y, Shi Y, Chen Z, Leung SW. Comparative efficacy of glimepiride and metformin in monotherapy of type 2 diabetes mellitus: meta-analysis of randomized controlled trials. Diabet Metab Synd. 2013;5(1):70.

24. Wulffele MG, Kooy A, de Zeeuw D, Stehouwer CD, Gansevoort RT. The effect of metformin on blood pressure, plasma cholesterol and triglycerides in type 2 diabetes mellitus: a systematic review. J Int Med 2004;256:1-14.

25. Garimella S, Seshayamma V, Rao HJ, Kumar S, Kumar U, Saheb SH. Effect of Metformin on Lipid profile of type II Diabetes. Int J Intg Med Sci. 2016;3(11):449-53.

26. Ingle PV, Talele DG. Comparative effects of metformin in combination with glimepiride and glibenclamide on lipid profile in indian patients with type 2 diabetes mellitus. Age. 2011;47:45.

27. Seuring T, Archangelidi O, Suhrcke M. The economic costs of type 2 diabetes: a global systemic review. Pharmacoeconom. 2015;33(8);811-31.

28. Nathan DM, Buse JB, Davidson MB, Heine RJ, Holman RR, Sherwin R, et al. Management of hyperglycemia in type 2 diabetes: a consensus algorithm for the initiation and adjustment of therapy: a consensus statement from the American Diabetes Association and the European Association for the Study of Diabetes. Diabet care. 2006;29(8):1963-72.

Cite this article as: Shashikala E, Motgi S, Rao RBNV, Sattar MA. Study of lipid lowering effects of oral antidiabetic drugs in type 2 diabetes mellitus patients. Int J Basic Clin Pharmacol 2018;7:126-32. 